\title{
Are blood tests of value in the primary assessment and resuscitation of patients in the $A \& E$ department?
}

\author{
A Pennycook
}

\begin{abstract}
Summary
Over a three month period an audit of the use of emergency blood tests was carried out in the accident and emergency (A\&E) department at Southampton General Hospital. Few blood tests were found to be useful in the primary assessment and treatment of patients by the attending doctors. Only cross-matching of blood, an amylase level and an arterial blood gases were felt to be consistently of clinical benefit in the acute management of the patient. The reasons for inappropriate investigations and possible solutions are discussed. Significant cost savings can be made, allowing for better targeting of resources.
\end{abstract}

Keywords: audit, accident and emergency medicine, blood tests

\section{Introduction}

The use of diagnostic tests has increased rapidly over the past 30 years and unnecessary testing may be commonplace in clinical practice. ${ }^{1,2}$ Requests for out-of-hours blood tests have been shown to have doubled in some laboratories during the mid 1980s. ${ }^{3}$ Worryingly, evidence exists that the results of many tests performed are either ignored or not acted on. ${ }^{4}$

Inappropriate investigations are often requested by inexperienced, inadequately supervised, junior doctors. Much has been written about the ordering of unneeded X-rays in relation to the accident and emergency (A\&E) departments, but little attention has been given to blood investigations and their clinical usefulness in this setting. Therefore, in order to assess the appropriateness and value of emergency blood tests taken and in particular to find out how helpful the attending doctor found the results in influencing their clinical management of the patient, an audit was undertaken in the A\&E department at Southampton General Hospital.

\section{Methods}

Guidelines were issued by the senior A\&E staff to the senior house officers at the commencement of their posts detailing which blood investigations were considered to be of value in a broad range of clinical conditions that commonly present to the $A \& E$ department (see box). Reinforcement of the guidelines and feedback from the senior house officers took place regularly at the weekly teaching sessions. This list was not exclusive and the doctors were encouraged to use their clinical initiative where appropriate. Thereafter, over a three-month period the senior house officers were asked to record various items of information on each occasion they took a blood sample (see box on following page).

Guidelines issued to senior house officers suggesting appropriate use of blood tests

Relevant investigations that are likely to be helpful in the primary assessment and resuscitation of the patient are:

Ischaemic chest pain Usually no blood tests are appropriate. The aim is thrombolysis at the earliest opportunity. Urea and electrolyte testing may be of value in the presence of arrythmias or previous diuretic therapy.

Cardiac arrest Arterial blood gases and urea and electrolytes in the post- resuscitative phase. Heart failure Arterial blood gases and urea and electrolytes.

Asthma Arterial blood gases.

Chronic obstructive airways disease Arterial blood gases

Diabetes mellitus Hyperglycaemia-glucose, urea and electrolytes, arterial blood gases and occasionally white blood cells

Hypoglycaemia-glucose and urea and electrolytes.

Gastrointestinal bleeding Cross- matching of blood for transfusion.

Poisoning Paracetamol levels, salicylate levels, urea and electrolytes, blood sugar and arterial blood gases. Occasionally other drug levels may be relevant, eg, phenytoin or theophylline.

Acute abdominal pain Amylase, urea and electrolytes (if significant vomiting or diarrhoea present). A full blood count is rarely indicated. Acute gynaecological problems Crossmatching of blood for transfusion and rarely a full blood count is indicated.

Trauma Cross-matching of blood for transfusion. Rarely a full blood count will be indicated.

Other blood tests may be appropriate to the acute management of a patient but should be focused on the clinical needs of the individual. 
Information recorded each time a blood test requested

1) The type of test(s) undertaken.

2) The provisional diagnosis prior to the sample being taken and clinical indication for each test.

3) Whether the results of the test(s) in each case:

- helped achieve the final diagnosis?

-influenced the decision to admit the patient or not?

- changed the patient's management in the $A \& E$ department or not and if so, in what manner?

-state if any other clinical benefits had been identified for the patient by having the test and record them.

4) The patient's final diagnosis on leaving the A\&E department after the result of the test was known.

5) Whether the patient was admitted or not and under which specialty.

\section{Results}

The investigations performed outwith the audit standards are shown in table 1 . The senior house officers retrospective impressions of the value of the individual tests are present below.

\section{FULL BLOOD COUNT}

The clinical indications were given in 117 instances (table 2); 102 full blood counts $(95.6 \%)$ were taken outwith the guidelines (table 1). Perceived benefits of the results are shown in table 3 and included establishing a baseline and establishing or excluding the presence of infection. No original provisional diagnosis was changed by a full blood count. have been unhelpful.

\section{UREA AND ELECTROLYTES}

The clinical indications given are shown in table 3; $92(94 \%)$ fell outwith the guidelines. No provisional diagnosis was changed followOverall, $98(83.7 \%)$ of the tests were stated to

ing urea and electrolyte tests. Perceived benefits (table 4) included establishing a baseline in 11, helping the in-patient teams in 15 and preparing the patient for theatre in four cases.

Table 2 Presumptive diagnoses of patients undergoing a full blood count

\begin{tabular}{lc}
\hline Diagnosis & Number \\
\hline Abdominal pain & 22 \\
Gastrointestinal bleeding & 18 \\
Myocardial infarction & 9 \\
Angina & 7 \\
Heart failure & 7 \\
Stroke & 6 \\
Collapse & 6 \\
Multiple trauma & 5 \\
Fractured femur & 4 \\
Fractured neck of femur & 3 \\
Other trauma & 6 \\
Seizure & 2 \\
Overdose salicylate & 2 \\
Pancreatitis & 2 \\
Miscellaneous conditions & 18 \\
\hline
\end{tabular}

Table 3 Presumptive diagnoses of patients undergoing testing of urea and electrolytes

\begin{tabular}{lc}
\hline Diagnosis & Number \\
\hline Self poisoning & 10 \\
Abdominal pain (? cause) & 10 \\
Myocardial infarction & 8 \\
Anginal-type pain & 8 \\
Isolated single trauma & 8 \\
Collapse (? cause) & 7 \\
Undiagnosed chest pain & 6 \\
Appendicitis & 6 \\
Gastrointestinal bleeding & 6 \\
Multiple trauma & 4 \\
Dysrrhythmia & 2 \\
Pancreatitis & 2 \\
Acute abdomen & 2 \\
Pyelonephritis & 2 \\
Stroke & 2 \\
Hypoglycaemia & 1 \\
Miscellaneous & 11 \\
\hline
\end{tabular}

Table 1 Investigations performed outwith the suggested guidelines by clinical grouping

\begin{tabular}{|c|c|c|c|c|c|c|c|c|}
\hline & $\begin{array}{l}\text { Full } \\
\text { blood } \\
\text { count }\end{array}$ & $\begin{array}{l}\text { Urea and } \\
\text { electrolytes }\end{array}$ & $\begin{array}{l}\text { Cardiac } \\
\text { enzymes }\end{array}$ & Glucose & Amylase & $\begin{array}{l}\text { Arterial } \\
\text { blood } \\
\text { gases }\end{array}$ & $\begin{array}{l}\text { Liver } \\
\text { function } \\
\text { tests }\end{array}$ & $\begin{array}{l}\text { Blood } \\
\text { group and } \\
\text { save }\end{array}$ \\
\hline $\begin{array}{l}\text { Ischaemic chest pain } \\
(\mathrm{n}=17)\end{array}$ & 11 & 16 & 7 & 3 & 1 & 1 & & \\
\hline $\begin{array}{l}\text { Non-specific chest } \\
\text { pain }(n=7)\end{array}$ & 4 & 4 & & & 1 & 2 & & \\
\hline $\begin{array}{l}\text { Heart failure } \\
\quad(\mathrm{n}=9)\end{array}$ & 7 & 8 & & 1 & & & & 1 \\
\hline $\begin{array}{l}\text { Asthma/bronchitis } \\
(\mathrm{n}=5)\end{array}$ & 1 & 1 & & & & & & \\
\hline $\begin{array}{l}\text { Diabetes }(n=3) \\
\text { Gastrointestinal }\end{array}$ & 1 & & & & & & & \\
\hline $\begin{array}{l}\text { bleeding } \\
(\mathrm{n}=15)\end{array}$ & 13 & 8 & & & 2 & & 1 & \\
\hline Poisonings $(n=40)$ & 5 & & & & & & & \\
\hline $\begin{array}{l}\text { Miscellaneous } \\
(\mathrm{n}=32)\end{array}$ & 18 & 30 & 3 & 3 & & & & \\
\hline $\begin{array}{l}\text { Acute abdominal pain } \\
(\mathbf{n}=32)\end{array}$ & 26 & 14 & & & & & & \\
\hline Trauma $(n=23)$ & 16 & 11 & & & & & & \\
\hline
\end{tabular}

^Included cerebrovascular attacks and seizures, one patient given 'geriatric screen'. 
AMYLASE

The amylase result was found useful in excluding pancreatitis in 26 patients (table 4 ).

\section{ARTERIAL BLOOD GASES}

The senior house officer's impressions are shown in table 4. The clinical indications given were respiratory distress/hypoxia in 16 cases, chest pain in two, gauge the severity of pancreatitis in two and airway obstruction in one. Four of these patients had carboxyhaemoglobin levels checked. This was consistently found to be diagnostic, to influence the decision to admit, and to change management.

\section{BLOOD GLUCOSE}

Clinical indications were mainly cardiovascular, eg, myocardial infarction in three cases and cerebrovascular accident in three and in seven patients for suspected complications of diabetes. This test was found to be useful (table 5), especially in excluding hypoglycaemia.

Table 4 Clinical usefulness of results in A\&E as determined by the attending senior house officer

\begin{tabular}{lllll}
\hline & $\begin{array}{l}\text { Full blood } \\
\text { count }\end{array}$ & $\begin{array}{l}\text { Urea and } \\
\text { electrocytes }\end{array}$ & Amylase & Blood gases \\
\hline Number of tests & 119 & 98 & 29 & 29 \\
$\begin{array}{l}\text { Number of tests after } \\
\quad 92\end{array}$ & 79 & 24 & 25 \\
$\quad \begin{array}{l}\text { Influenced diagnosis } \\
\text { Influenced decision to }\end{array}$ & 20 & 3 & 15 & 11 \\
$\quad 21$ & 4 & 11 & 11 \\
$\quad \begin{array}{l}\text { admit or not } \\
\text { Chanbers admitted }\end{array}$ & 97 & 86 & 17 & 21 \\
$\quad$ care in A\&E & 2 & 2 & 0 & 14 \\
\hline
\end{tabular}

Table 5 Clinical usefulness of results in $A \& E$ as determined by the attending senior house officer

\begin{tabular}{lllll}
\hline & $\begin{array}{l}\text { Blood } \\
\text { glucose }\end{array}$ & Paracetamol & Salicylate & Cross-match \\
\hline $\begin{array}{l}\text { Number of tests } \\
\text { Number of tests after }\end{array}$ & 16 & 36 & 30 & 23 \\
$\quad 15$ & 29 & 24 & 21 \\
$\quad \begin{array}{l}\text { Influenced diagnosis } \\
\text { Influenced decision to }\end{array}$ & 4 & 21 & 24 & 0 \\
$\quad 1$ & 20 & 11 & 0 \\
$\quad \begin{array}{l}\text { Numit or not } \\
\text { Changers admitted }\end{array} \quad 12$ & 24 & 25 & 22 \\
$\quad$ care in A\&E & 1 & 14 & 0 & 6 \\
\hline
\end{tabular}

Table 6 Clinical usefulness of results in A\&E as determined by the attending senior house officer

\begin{tabular}{llll}
\hline & $\begin{array}{l}\text { Cardiac } \\
\text { enzymes }\end{array}$ & $\begin{array}{l}\text { Liver function } \\
\text { tests }\end{array}$ & $\begin{array}{l}\text { Clotting } \\
\text { studies }\end{array}$ \\
\hline $\begin{array}{l}\text { Number of tests } \\
\text { Number of tests after }\end{array}$ & 11 & 3 & 12 \\
$\quad 7$ & 1 & 7 \\
$\begin{array}{l}\text { Influenced diagnosis } \\
\begin{array}{l}\text { Influenced decision to } \\
\text { admit or not }\end{array}\end{array}$ & 0 & 0 & 0 \\
$\begin{array}{l}\text { Numbers admitted } \\
\text { Changed patient's clinical }\end{array}$ & 11 & 0 & 0 \\
$\quad$ care in A\&E & 0 & 3 & 12 \\
\hline
\end{tabular}

SALICYLATE AND PARACETAMOL LEVELS

Drug levels were found to be generally useful in excluding or confirming significant poisoning (table 5). Following paracetamol levels, six patients received parvolex. A salicylate overdose was excluded in 24 instances.

\section{CROSSMATCH OF BLOOD}

Clinical indications varied from 'bleeding to death' to a precautionary measure. The underlying diagnoses were multiple trauma, significant isolated trauma, gastro-intestinal bleeding and suspected intra-abdominal perforation. Six patients subsequently received a transfusion (table 5).

Twenty-seven patients had blood grouped and saved, 21 out of hours. This was not felt to influence patient care in the $A \& E$ department, all patients being admitted. The main clinical indication was precautionary in 23 cases. The common provisional diagnoses were upper gastrointestinal bleeding and trauma.

\section{CARDIAC ENZYMES}

The results were not available to the senior house officers and consequently this test was not thought to influence the patients' care in the A\&E department (table 6). Clinical indications were proven infarct in five cases, anginal pain in four and dysrhythmmia in the remaining two patients. Perceived benefits of the test being taken in the $A \& E$ department were timeefficiency and helping the receiving teams in five instances.

\section{LIVER FUNCTION TESTS}

Clinical indications included a paracetamol overdose more than 12 hours previously, a patient who was jaundiced and one who presented with a gastro-intestinal bleed. No benefit was perceived with regard to the patient's care in the $A \& E$ department (table 6).

\section{CLOTTING STUDIES}

Clinical indications included presumed paracetamol poisoning in five, gastro-intestinal bleeding in five and following trauma in two. The results were not felt to have influenced clinical management in the A\&E department (table 6).

\section{OTHER TESTS}

Six blood cultures, one sample for syphylis serology, two for urate, four for hepatitis serology, one for viral screen and one sample for serum alcohol were taken. Only the latter was felt to influence the patients' care whilst in the $A \& E$ department.

\section{Discussion}

This audit demonstrates that the senior house officers did not limit their use of blood investigations to within the guidelines set by the senior A\&E staff. The standards suggested were minimum ones and it was implicit that the senior house officers could perform additional tests if clinically indicated in an individual patient. However, a definite pattern of inappropriate investigation is strongly suggested by 
the large number of tests in which the audit criteria were exceeded (table 1).

The most common investigation was a full blood count (table 2). $95.6 \%$ of which fell outwith the guidelines. Interestingly, the result, if known, only rarely aided the diagnosis or altered the decision to admit and actually changed the patient's care in only two instances (table 4). The emphasis placed on the reliability of the white blood cell count as an indicator of the presence and severity of infection is of particular concern as a low or high white blood cell count alone is unreliable in this context. Of more relevance in the $A \& E$ department is the clinical condition of the patient.

A large proportion of the urea and electrolyte tests $(94 \%)$ were taken outwith the guidelines (table 1). Overall, the senior house officers did not find the results helpful (table 4). Only rarely was the patient's diagnosis or management changed in the A\&E department. This would suggest that the urea and electrolyte tests were often undertaken on an indiscriminate screening basis, with little clinical benefit for the patients tested.

Not unsurprisingly, cardiac enzymes measured in the $A \& E$ department did not provide any benefit to the patient in that setting. Nor was blood taken for liver function tests, a clotting screen, cultures, urate levels or for virology perceived to be helpful.

Other tests proved more relevant. Arterial blood gases often aided the diagnosis, influenced the case for admission and regularly changed the patients' actual management in the A\&E department (table 4). Also, the measurement of carboxyhaemoglobin levels consistently proved relevant, as did the estimation of serum amylase in the differential diagnosis of abdominal pain. Salicylate and paracetamol levels were found to be vital in confirming the diagnosis of poisoning and indicating the need for treatment (table 5). A glucose result was important in confirming a diagnosis, but less so at changing the patients' treatment (table 5). Presumably, therapeutic action would have already been taken on the basis of a BM stick result.

Blood for cross-matching (table 5) and group and save was taken in a variety of clinical situations, six patients receiving an actual transfusion in the A\&E department. Precautionary cross-matching or group and save is appropriate in the emergency setting, but if only $12 \%$ of patients received blood, then stricter guidelines may be required.

The vast majority of investigations were taken out of normal working hours. This may in part be due to the lack of senior $A \& E$ presence directly on the departmental floor, the tests being perceived by the attending senior house officers to be necessary to back up their clinical decision. However, this study clearly demonstrates that many of the tests carried out by the senior house officers did not help them at all in their diagnosis and management of their patients in the A\&E setting. This especially applies to the many unnecessary full blood counts and urea and electrolyte samples. This finding is supported by Sandler ${ }^{6}$ who found that in a two year evaluation of emergency investigations in the management of acute medical admissions only $17 \%$ were abnormal. He concluded that only an arterial blood gases in respiratory conditions, a glucose in diabetes, and an amylase in abdominal pain were of consistent value and that in most medical emergencies, urea and electrolyte testing was entirely unhelpful. Roux ${ }^{7}$ recently looked at the value of pre-operative blood investigations in the anaesthetic assessment of emergency adult trauma patients and concluded that only arterial blood gases gave relevant information in addition to the clinical examination, the value of other emergency tests being minimal.

Many of the tests were probably at the request of the in-hospital receiving teams. Some of the results are likely not to have been sought or acted on by the A\&E doctors. This practice is only reasonable if the results will benefit the patient in the hours immediately after admission: Taking the sample, filling in the forms, then contacting the laboratories and blood porter is time-consuming. Senior house officers are under immense pressure to see and treat patients in the $A \& E$ department quickly to meet quality standards in the national and local patients' charters. ${ }^{8}$ Their role is the primary

Guidelines issued to senior house officers post-audit suggesting appropriate use of blood tests

Relevant investigations that are likely to be helpful in the primary assessment and resuscitation of the patient are:

Ischaemic chest pain Usually no blood tests are appropriate. The aim is thrombolysis at the earliest opportunity. Urea and electrolyte testing may be of value in the presence of arrythmias or previous diuretic therapy.

Cardiac arrest Arterial blood gases and urea and electrolytes in the post- resuscitative phase and venous gases and urea and electrolytes during resuscitation.

Heart failure Arterial blood gases and urea and electrolytes.

Asthma Arterial blood gases.

Chronic obstructive airways disease Arterial blood gases.

Diabetes mellitus Hyperglycaemia-glucose, urea and electrolytes, arterial blood gases and occasionally white blood cells

Hypoglycaemia-glucose and urea and electrolyte.

Gastrointestinal bleeding Cross- matching of blood for transfusion.

Poisoning Paracetamol levels, salicylate levels, urea and electrolytes, glucose and arterial blood gases. Occasionally other drug levels may be relevant, eg, phenytoin or theophylline. Acute abdominal pain Amylase, urea and electrolytes (if significant vomiting or diarrhoea present). A full blood count is rarely indicated. Acute gynaecological problems Crossmatching of blood for transfusion and rarely a full blood count is indicated.

Trauma Cross-matching of blood for transfusion. Rarely a full blood count will be indicated.

Other blood tests may be appropriate to the acute management of a patient but should be focused on the clinical needs of the individual. 
assessment and treatment of patients, not to act as a phlebotomy service for the rest of the hospital. Further, with cross-charging a reality in many hospitals, inappropriate investigations that do not benefit the patient whilst they are being cared for in the $A \& E$ department are a waste of scant A\&E resources. Most of the patients who had inappropriate tests taken were admitted by the medical, orthopaedic or general surgery directorates and it could be argued that, to some extent, these disciplines are being subsidised by the $A \& E$ budget in financial, equipment, and manpower terms.

Emergency tests have little to offer in aiding either diagnosis or treatment ${ }^{6}$ and should only be considered specifically in the context of the individual patient's history and clinical examination. The taking of blood routinely for screening in the emergency situation (eg, in the management of trauma) as advocated by some authorities $^{9}$ is not desirable. The introduction of guidelines can temporarily reduce the demand for blood tests from clinicians. Gyde ${ }^{10}$ found that specific guidelines reduced the demand for laboratory tests by $64 \%$ in the first year, but that subsequently the demands for tests gradually rose, perhaps due to increased clinical workload. Therefore, adequate continuing education of junior doctors to the limited value of blood tests is essential. This education needs to begin during the undergraduate curriculum. The minimal value of a normal test in excluding a diagnosis that is not already suggested by the clinical condition of the patient needs to be emphasized. Senior medical support is mandatory for the success of any guidelines to limit unnecessary tests, as is close liaison by clinicians with their colleagues in the laboratory services. ${ }^{11}$

The results of this audit have allowed our department to change practice and implement guidelines on the use of blood tests based on the standards originally proposed (see boxes). If the attending doctor wishes for clinical reasons to deviate from the suggested protocols, then contact must be sought from the senior $A \& E$ doctor on call. Considerable savings (approximately $40 \%$ of previous monthly costs) on out-of-normal-hours investigations have been made over the past 12 months with no apparent deleterious effects on patient care and no negative feedback from the in-patient specialities. All A\&E departments should implement clear guidelines to aid senior house officers to use blood investigations appropriately, to achieve high quality clinical care on a cost-effective basis.

The author wishes to thank Dr Sleet and Miss Williams, Consultants in A\&E Medicine, for permission to study their patients and for their advice and support in preparing this manuscript.
1 Fowkes FGR, Hall R, Jones JH et al. Trial of strategy for reducing the use of laboratory tests. $B M 7$ 1986; $292: 883-5$. 2 Young DW. Improving laboratory usage: a review. Postgrad Med $\Im$ 1984; 64: 283 .

3 Legg EF. The on-call service: a regional survey. Ann Clin Biochem 1989; 26: 19-25.

4 Stilwell J, Young DW, Cunnington A. Evaluation of laboratory tests in hospital. Ann Clin Biochem 1980; 17: 281-6.

5 RCR Working Party. Making the best use of a Department of Radiology. Guidelines for Doctors. London: Royal College of Radiologists, 1989.

6 Sandler G. Do emergency tests help in the management of acute medical admissions? BMf 1984; 289: 973-7.
7 Roux A, Lourens L, Richards E. Contribution of preoperative investigations to the anaesthetic management preoperative investigations to the anaesthetic manag

8 National Patients Charter for the NHS. London: HMSO, 1991 .

9 Cullen BF. A practical approach to anaesthesia for trauma. Am Soc Anaesthesiol Annu Refresher Course Lectures. 1990; p 161

0 Gyde OHB, Leyland MJ. Rational restriction of out of hours requests for haematology tests. $B M \mathcal{F} 1989,298: 1291-2$.

11 Fraser LG, Woodford FP. Strategies to modify the test requesting patterns of clinicians. Ann Clin Biochem 1987; 24: 223-31. 